\section{The Development of Teaching Media Video Instructional Book at The Student Courses Technology Education, Faculty of Education University State Makassar}

\author{
Amir ${ }^{1}$ dan Mesach Dayunison Parumbuan ${ }^{2}$ \\ Fakultas Ilmu Pendidikan \\ Universitas Negeri Makassar \\ Email:amirtosuppa@yahoo.co.id ${ }^{1}$
}

http://ojs.unm.ac.id/index.php/Insani/index

Abstract. This study aims to develop and produce a video media development textbook to be used in lectures/learning courses on video media development for students of Educational Technology Study Program, Faculty of Education, Makassar State University. This type of research is research and development ( $R$ \& D) with the Four-D (4D) development model by S. Thiagarajan and Semmel (1994). Research subjects included: experts in the field of study / content learning, learning media experts, textbook design experts, and students of Educational Technology Study Program. Data was recorded by questionnaire and test techniques. Data were analyzed by descriptive and quantitative qualitative statistics. The results showed that the video media development textbook developed with the Four D model (4D) met the criteria of valid, practical, and effective.

Kata Kunci: Teaching Book, Learning Video, Research and Development

\section{INDONESIAN JOURNAL OF EDUCATIONAL STUDIES (IJES)}

\author{
E-ISSN: 2621-6744 \\ P-ISSN: 2621-6736 \\ Submitted: June $22^{\text {nd }} 2018$ \\ Accepted: July $5^{\text {th }} 2018$
}

Abstract. This study aims to develop and produce a video media development textbook to be used in lectures/learning courses on video media development for students of Educational Technology Study Program, Faculty of Education, Makassar State University. This type of research is research and development $(R \& D)$ with the Four-D (4D) development model by $S$. Thiagarajan and Semmel (1994). Research subjects included: experts in the field of study / content learning, learning media experts, textbook design experts, and students of Educational Technology Study Program. Data was recorded by questionnaire and test techniques. Data were analyzed by descriptive and quantitative qualitative statistics. The results showed that the video media development textbook developed with the Four $D$ model (4D) met the criteria of valid, practical, and effective. 


\section{PENDAHULUAN}

Peningkatan mutu pendidikan pada pendidikan tinggi adalah suatu keniscayaan. Kemajuan ilmu pengetahuan dan teknologi serta seni (IPTEKS) telah mendorong munculnya disiplin ilmu baru, semakin kaburnya batasan suatu disiplin ilmu, sehingga menyebabkan munculnya spesialisasi-spesia-lisasi baru dalam bidang pekerjaan, serta arus globalisasi yang semakin pesat dimana pekerja dan produk asing terus masuk ke dalam negeri menyebabkan persaingan yang semakin ketat dan berat. Dalam Undang-Undang Republik Indonesia Nomor 12 Tahun 2012 Tentang Pendidikan Tinggi, pasal 5 ayat a dan b, mengamanatkan bahwa pendidikan tinggi bertujuan: a) berkembangnya potensi mahasiswa agar menjadi manusia yang beriman dan bertakwa kepada Tuhan Yang Maha Esa dan berakhlak mulia, sehat berilmu, cakap, kreatif, mandiri, terampil, kompeten, dan berbudaya untuk kepentingan bangsa; b) dihasilkannya lulusan yang menguasai cabang Ilmu Pengetahuan dan/atau Teknologi untuk memenuhi kepentingan nasional dan peningkatan daya saing bangsa. Oleh sebab itu, pendidikan tinggi sebagai wadah untuk mengembangkan ilmu pengetahuan dan teknologi serta seni harus bisa meningkatkan mutu dari proses dan hasil pendidikannya untuk dapat meningkatkan daya saing bangsa Indonesia. Dalam hal ini proses pembelajaran dan lulusan yang bermutu.

Universitas Negeri Makassar sebagai salah satu institusi pendidikan tinggi yang mendukung tercapainya tujuan pendidikan tinggi, memiliki visi sebagai pusat pendidikan, pengkajian, dan pengembangan pendidikan, sains, teknologi, dan seni berwawasan kependidikan dan kewira-usahaan. Serta misi menghasilkan sumber daya manusia profesional di bidang kependidikan dan nonkependidikan; memberikan layanan kepada masyarakat luas untuk peningkatan kualitas hidup masyarakat, bangsa, dan negara; dan mengembangkan lembaga (universitas) menjadi teaching and research university yang dapat memenuhi kebutuhan bangsa. Program studi Teknologi Pendidikan sebagai salah satu program studi yang berada dalam lingkup Fakultas Ilmu Pendidikan Universitas Negeri Makassar berkomitmen untuk turut mendukung usaha pemerintah dalam meningkatkan mutu proses dan hasil pendidikan/pembelajaran. Penyediaan sumber-sumber belajar yang sesuai dengan kebutuhan mahasiswa dan melaksanakan kegiatan pem-belajaran yang autentik sesuai dengan bidang keahlian mahasiswa prodi teknologi pendi-dikan sebagai calon teknolog pembelajaran.

Proses dan hasil pendidikan adalah dua hal yang tidak dapat dipisakan, jika proses berkualitas dapat dipastikan hasil akan berkualitas. Demikian sebaliknya, hasil yang berkualitas hanya dapat dicapai dari proses yang berkualitas. Proses pendidikan khususnya pembelajaran yang berkualitas tidak terlepas dari unsur pendidik, kurikulum, sarana dan prasarana dan tersedianya sumber-sumber belajar yang sesuai dengan kebutuhan mahasiswa. Sanjaya (2012: 32) menyatakan bahwa "proses pembelajaran akan efektif manakala memanfaatkan berbagai sarana dan prasarana yang tersedia termasuk meman-faatkan berbagai sumber belajar”. Oleh sebab itu, ketersediaan sumber belajar sebagai salah satu faktor peningkatan kualitas pendidikan harus dipenuhi. 


\section{Indonesian Journal of Educational Studies Vol.21, No.2, December 2018}

Sumber belajar mencakup apa saja yang dapat digunakan dalam membantu tiap orang untuk belajar dan menampilkan kompetensi (Seels dan Richey, 1994: 13). Lebih spesifik AECT (1997: 9) menyatakan bahwa sumber belajar dapat dibedakan menjadi dua jenis sebagai berikut: (a) sumber belajar yang direncanakan (by design), yaitu semua sumber belajar yang secara khusus telah dikem-bangkan sebagai "komponen sistem instruksional" untuk memberikan fasilitas belajar terarah dan bersifat formal, dan (b) sumber belajar karena dimanfaatkan (by utilitzation), yaitu sumber-sumber yang tidak secara khusus didesain untuk keperluan pem-belajaran namun dapat ditemukan, diaplikasi-kan, dan digunakan untuk keperluan belajar.

Buku ajar merupakan sumber belajar yang khusus dikembangkan sebagai sumber belajar utama dalam proses pembelajaran. Buku ajar adalah buku pegangan untuk suatu matakuliah yang ditulis dan disusun oleh pakar bidang terkait dan memenuhi kaidah buku teks serta diterbitkan secara resmi dan disebarluaskan (Pedoman PAK Dosen, 2014). Menurut penelitian dan pengembangan buku ajar statistik yang dilakukan oleh Sa'idah (2016), menunjukkan bahwa uji kepraktisan buku ajar oleh mahasiswa mendapat skor rata-rata 92,5 yang berarti sangat baik atau praktis digunakan sebagai acuan sumber belajar pada perkuliahan statistik.

Menurut penelitian oleh Kurniawan dan Nurlela (2013) menunjukkan bahwa aktivitas siswa selama pembelajaran menggunakan buku ajar materi pembuatan cornflake cookies mendapatkan nilai sangat baik yaitu dengan skor keterlaksanaan yaitu $85 \%$, hasil belajar siswa setelah menggunakan buku ajar materi pembuatan cornflake cookies dapat dikatakan melampaui batas KKM yang telah ditentukan oleh pihak sekolah yaitu dengan nilai rat-arata kelas yaitu 72 dan respon siswa terhadap buku siswa yang dikembangkan mencapai kriteria sangat baik yaitu dengan persentase 91,6\%. Buku ajar memiliki keunggulan dibandingkan dengan buku teks, antara lain (1) berusaha menimbulkan minat baca, (2) dirancang dan ditulis untuk mahasiswa, (3) menjelaskan tujuan pembelajaran, (4) dipergunakan oleh dosen dan mahasiswa dalam proses perkuliahan, (5) disusun berdasarkan pola pembelajaran yang fleksibel, sistematis dan terstruktur berdasarkan kebutuhan mahasiswa dan kompetensi akhir yang ingin dicapai, (6) fokus pada pemberian kesempatan bagi mahasiswa untuk berlatih, (7) memberi rangkuman, (8) gaya penulisan komunikatif, (9) ada umpan balik, (10) mengakomodasi kesulitan belajar mahasiswa, dan (11) menjelaskan cara mempelajari buku ajar.

Memperhatikan pentingnya sumber belajar berupa buku ajar dalam proses pembelajaran maka setiap pendidik utamanya dosen seyogyanya mengembangkan buku ajar agar proses pembelajaran berjalan efektif dan efisien untuk mencapai tujuan dan mening-katkan kualitas pembelajaran. Namun Kenya-taan di lapangan belum semua pendidik memahami pentingnya menyediakan buku ajar sebagai salah satu sumber belajar, seperti halnya pada mata kuliah pengembangan media video pembelajaran di program studi Tek-nologi Pendidikan Fakultas Ilmu Pendidkan Universitas Negeri Makassar, belum memiliki buku ajar yang digunakan dalam proses pembelajaran, sehingga berdampak pada tidak terstrukturnya dengan baik kompentensi atau pengetahuan yang dimiliki oleh mahasiswa.

Berdasarkan pemaparan di atas maka, tujuan penelitian dan pengembangan ini ialah untuk mengembangkan buku ajar mata kuliah pengembangan media video 
pembelajaran pada program studi Teknologi Pendidikan Fakultas IImu Pendidikan Universitas Negeri Makassar, agar dapat meningkatkan proses dan hasil pembelajaran yang berkualitas.

\section{MEDIA PEMBELAJARAN}

Istilah media berasal dari bahasa Latin yang merupakan bentuk jamak dari "medium" yang secara harafiah berarti perantara atau pengantar. Menurut Sanjaya (2014) media adalah perantara dari sumber informasi ke penerima informasi, contohnya video, televisi, komputer dan lain sebagainya". Media dimanfaatkan untuk menjembatani antara pengirim atau sumber informasi ke pada penerima informasi. Demikian media sebagai peratara antara sumber informasi kepada penerima informasi dapat dianalogikan seperti sungai yang menyalurkan air dari sumber air kepada masyarakat sebagai pengguna atau yang memanfaatkan air tersebut. Media dalam konteks pembelajaran bukan hanya sekadar perantara, namun lebih dari pada itu, yaitu media berfungsi sebagai sumber belajar yang dirancang untuk digunakan dalam proses pembelajaran. Menurut Gerlach dan Ely (dalam Sanjaya, 2014), "secara umum media pembelajaran adalah meliputi orang, bahan, peralatan, latar/lingkungan, dan kegiatan yang menciptakan kondisi yang memungkinkan peserta didik memerolah pengetahuan, keterampilan, dan sikap". Media pembelajaran tidak merujuk pada orang, bahan, peralatan, latar/lingkungan, dan kegiatan tanpa adanya tujuan untuk membelajarkan peserta didik, tetapi media pembelajaran memungkinkan peserta didik memperoleh pengetahuan, keterampilan dan sikap yang diinginkan.

Menurut Sanjaya (2014: 118), media pembelajaran dapat diklasifikasikan menjadi beberapa klasifikasi bergantung dari sudut mana melihatnya. a) Dilihat dari sifanya, media dapat dibagi ke dalam media auditif, media visual, media audio visual, b) Dilihat dari kemampuan jangkauannya media dapat dibagi ke dalam media yang memiliki daya liput luas dan serentak, mempunyai daya liput yang terbatas oleh ruang dan waktu, c) Dilihat dari cara atau teknik pemakaiannya media dapat dibagi ke dalam media yang diproyeksikan, dan media yang tidak diproyeksikan, d) Media juga dapat dikelompokkan berdasarkan bentuk dan cara penyajiannya.

Klasifikasi atau pengelompokan media pembelajaran telah banyak dikemukakan oleh ahli, di antaranya seperti Rudy Bretz (1972) dalam Sadiman (2011: 21) mengidentifikasi media dari tiga unsur pokok yaitu, suara, visual, dan gerak. Briggs (1970) dalam Sadiman (2011: 2) mengklasifikasi 13 macam media yang digunakan dalam proses pembelajaran, yaitu objek, model, suara langsung, rekaman audio, media cetak, pembelajaran terprogram, papan tulis, media trans-paransi, film rangkai, film, televisi, dan gambar. Kemp dan Dayton (1985) dalam Arsyad (2014: 39) mengelompok-kan media ke dalam delapan jenis, yaitu media cetak, media panjang, overhead trans-parency, rekaman audio tape, seri slide dan film stripe, penyajian multi image, rekaman video, dan film hidup dan komputer. Berdasarkan pengelompokan yang dikemukakan oleh beberapa ahli tesebut dapat disimpulkan bahwa peng-klasifikasian media-media tersebut ber-dasarkan saluran (channel) penerima pada manusia dan pada karakteristik menurut stimulus yang dapat ditimbulkan. 


\section{Indonesian Journal of Educational Studies Vol.21, No.2, December 2018}

Seels dan Glasgow (1990) dalam Sanjaya (2014: 123) mengelompokkan media pembelajaran ke dalam dua klasifikasi yaitu media tradisional dan media teknologi mutakhir. Media tradisi-onal, termasuk di dalamnya visual diam yang diproyeksikan (proyeksi overhead, slides, film stripe), visual yang tidak diproyeksikan (gambar, poster, foto, chart, grafik), audio (rekaman piringan, pita kaset), penyajian multimedia (slide plus suara (tape), multi image), visual dinamis yang diproyeksikan (film, televisi, video), cetak (buku teks, modul, majalah ilmiah), permainan (teka-teki, simulasi), dan realita (model, specimen (contoh), manipulatif (peta, boneka). Sedangan media teknologi mutakhir, terdiri atas media berbasis telekomunikasi (telekon-fernsi, kuliah jarak jauh), dan media berbasis mikro-prosessor (komputer, interaktif, compact disk). Berdasarkan klasifikasi media pembelajaran yang telah dikemukakan oleh para ahli di atas maka buku ajar pengembangan media video dikelompok-kan ke dalam media visual, media cetak, media tradisional.

Menurut Sanjaya (2014: 70), secara khusus media pembelajaran memilki manfaat dan fungsi sebagai berikut:

a. Manfaat Media Pembelajaran

1) Menangkap suatu objek peristwa tertentu.

2) Memanipulasi keadaan, peristiwa, atau objek tertentu.

3) Menambah gairah dan motivasi belajar siswa.

b. Fungsi Media Pembelajaran

1) Fungsi komunikatif. Media pembel-ajaran digunakan untuk memudahkan proses komunikasi antara pengirim pesan deagan penerima pesan. Jadi media dapat menjembatani keterbatas-an-keterbatasan dalam penyampaian pesan secara verbal.

2) Fungsi motivasi. Kemampuan suatu media menyajikan pesan dalam beragam format dan unsur dapat meningkatkan motivasi peserta didik. Jadi, dengan menggunakan media pembelajaran diharapkan peserta didik akan lebih termotivasi dalam pembelajaran.

3) Fungsi kebermaknaan. Melalui peng-gunaan media, pembelajaran dapat lebih bermakna, yakni pembelajaran bukan hanya dapat meningkatkan penambahan informasi berupa data dan fakta sebagai pengembang aspek kognitif tahap rendah, akan tetapi dapat meningkatkan kemampuan peserta didik untuk menganalisis dan mencipta sebagai aspek kognitif tahap tinggi.

4) Fungsi penyamaan persepsi. Melalui pemanfaatan media pembelajaran, diharapkan dapat menyamakan per-sepsi setiap peserta didik, sehingga setiap peserta didik memiliki pan-dangan yang sama terhadap informasi yang disuguhkan.

5) Fungsi individualitas. Pemanfaatan media pembelajaran berfungsi untuk dapat melayani kebutuhan setiap individu yang memiliki minat dan gaya belajar yang berbeda.

Menurut Degeng (2013: 163) sekurang-kurangnya ada lima cara dalam mengklasifikasikan media pembelajaran untuk keperluan mempreskripsikan strategi penyampaian, yaitu a) tingkat kecermatan representasi, b) tingkat interaktif yang mampu ditimbulkannya, c) tingkat kemam-puan khusus yang dimilikinya, d) tingkat motivasi yang mampu ditimbulkannya, dan e) tingkat biaya yang diperlukan. 
a) Tingkat Kecermatan Representasi: Meletakkan media pada suatu garis kontinum, seperti: benda konkret, media pandang-dengar, seperti film bersuara; media pandang, seperti gambar, atau diagram; media dengar, seperti rekaman suara dan simbul-simbul tertulis bisa memudahkan dalam penggunaan suatu media pembelajaran.

b) Tingkat Interaksi yang Mampu Ditimbulkanya: Tingkat interaksi yang mampu ditimbulkan oleh suatu media juga dapat dibentangkan dalam suatu kontinum, tetapi titik-titik dalm kontinum ini diunjukkan oleh jenis media yang berbeda: komputer, guru, buku kerja, buku teks/rekaman, dan siaran radio/televisi.

c) Tingkat Kemampuan Khusus yang Dimilikinya: Tingkat kemampuan khusus yang dimiliki oleh suatu media jug adapt dipakai untuk mempreskripskan strategi penyam-paian. Kemampuan-kemampuan khusus dari suatu media dapat dilihat dari kecepatannya dalam menyajian sesuatu.

d) Tingkat Motivasi yang Mampu Ditimbulkannya: Suatu media pembelajaran bisa member pengaruh motivasional yang berbeda. Makin dekat kesamaan dengan karakteristik pebelajar dengan media yang dipakai, makin tinggi pengaruh moivasional yang bisa ditimbulkanoleh media itu.

e) Tingkat Biaya yang Diperlukan: Tingkat biaya yang diperlukan dalam menyiapkan suatu media juga penting untuk mempreskripsikan strategi pnyampaian. Mulai perancangan sampai pem-buatannya, jika menggunakan media buatan sendiri. Tetapi jika menggunakan media siap pakai, dengan membeli, harganya berapa harus dipertmbangkan. Jadi, makin tepat dan lengkap media yang dipakai, makin besar keefektifan dari strategi penyampaian itu.

\section{MEDIA VIDEO PEMBELAJARAN}

Menurut Seels dan Glasgow (1990) media video tergolong dalam media tradisional (visual dinamis yang diproyek-sikan) (Sanjaya, 2014). Smaldino Lowther dan Russel mendefinisikan video sebagai media penyimpanan elektronik untuk gambar bergerak seperti kaset video, DVD, video berbasis komputer, dan video internet (Smaldino Lowther dan Russel (2008: 309). Arsyad (2011: 49) menyata-kan bahwa video merupakan gambar-gambar dalam frame, di mana frame demi frame diproyeksikan melalui lensa proyektor secara mekanis sehingga pada layar terlihat gambar hidup. Berdasarkan batasan yang dikemukakan oleh beberapa ahli di atas dapat disimpulkan bahwa media video tergolong sebagai media tradisional, media penyimpanan elektronik untuk gambar bergerak, dan merupakan gambar-gambar dalam frame. Media video sebagaimana didefinisi-kan oleh ahli di atas sudah sangat sering digunakan dalam proses pembel-ajaran. Misalnya, untuk menyajikan materi pelajaran yang sulit untuk dapat diamatai secara langsung seperti hewan buas, benda-benda langit dan sebagainya.

Smaldino, Lowther, dan Russel, (2008) mengelompokkan manfaat media video dalam pembelajaran berdasarkan kemampuan kognitif, afektif, psikomotor, interpersonal. Kognitif berkaitan dengan kemampuan seseorang dalam menerima informasi, afektif berkaitan dengan kemampuan menyikapi suatu peristiwa atau fakta, psikomotorik berkaitan dengan kemampuan menampilkan pengusaan suatu 


\section{Indonesian Journal of Educational Studies Vol.21, No.2, December 2018}

gerakan, dan interpersonal berkaitan dengan kemampuan bekerjasama, menjalin hubungan dengan orang lain.

a) Domain Kognitif. Media video dapat meningkatkan kemampuan membaca menunjukkan proses, hubungan, dan teknik.

b) Domain Afektif. Kemampuan video menyajikan gambar bergerak dan hidup sangat mampu mempengaruhi sisi emosional pebelajar dalam membentuk personal dan sikapnya.

c) Domain Psikomotor. Video memiliki kemampuan yang sangat kuat dalam menunjukkan cara kerja sesuatu.

d) Domain Interpersonal. Dengan menyaksikan program video bersama-sama, kelompok yang berbeda dapat membangun pemaham dasar sama untuk menjadi landasan dalam memulai diskusi.

\section{METODE PENELITIAN}

Jenis penelitian ini adalah penelitian dan pengembangan atau Research and Develop-ment (R\&D). Penelitian ini bertujuan mengembangkan dan menghasilkan produk berupa buku ajar pengembangan media video yang valid, praktis dan efektif. Model pengembangan yang digunakan adalah model Four-D (4D) oleh S. Thiagarajan dan Semmel (1994) yang terdiri dari empat (4) tahap, yaitu Define (pendefinisian), Design (perancangan), Develop (pengembangan), dan Disseminate (penyebaran) (Trianto, 2011). Model penelitian dan pengembangan yang digunakan dalam pengembangan produk buku ajar pengembangan media video ini adalah model Four D (4D) (Define, Design, Develop, Disseminate) atau pendefinisian, perancangan, pengembangan, dan penyebar-luasan yang dikembangkan oleh $\mathrm{S}$. Thiagarajan, Dorothy S. Semmel dan Melvin I. Semmel (1974). Model pengembangan ini dipilih sebagai model pengembangan buku ajar pengembangan media video karena tahapan pengembangan yang sederhana, sistematis, terperinci dan mudah dilaksanakan serta sangat sesuai dipakai dalam pengembangan buku ajar. Berikut bagan alur pengembangan buku ajar pengembangan media video dengan model Four D (4D).

a. Tahap Pertama: Penentuan Mata Kuliah yang dikembangkan: Pengembangan Media Video

b. Tahap Kedua: Pelaksanaan Pengembangan, yang terdiri atas 1) Define: pada tahap ini ditetapkan dan didefiniskan syarat-syarat pembelajaran, meliputi: tujuan pembelajaran dan pem-batasan isi pembelajaran. 2) Design: pada tahap ini merancang protipe pembelajaran, meliputi soal tes dan pengembangan isi pembelajaran. 3) Develop: pada tahap ini mengembangkan dan menghasilkan produk buku ajar sebelum diuji ahli dan uji coba lapangan. 4) Disseminate: pada tahap ini produk buku disebarkan kepada mahasiswa sebagai rujukan utama pada perkuliahan/pem-belajaran mata kuliah pengembangan media video.

c. Tahap Ketiga: Pengembangan Buku Ajar Pengembangan Media Video Pada tahap ketiga ini komponen-komponen buku ajar dikembangkan/diuraikan secara panjang lebar sesuai dengan fungsinya.

d. Tahap Keempat: Pelaksanaan Uji Ahli dan Uji Coba Lapangan. Produk Buku Ajar Pengembangan Media Video divalidasi oleh ahli bidang studi/isi pembelajaran, 
ahli media pembelajaran, ahli desain buku ajar, dan uji coba lapangan pada mahasiswa. Hasil validasi ahli dan uji coba lapangan dianalisis dan direvisi. Hasil analisis dijadikan dasar merevisi (revisi I dan revisi II). Hasil revisi I dan II dijadikan dasar untuk mencetak dan memperbanyak.

\section{HASIL DAN PEMBAHASAN}

Produk buku ajar pengembangan media video baik isi (teks dan gambar), media grafis berupa foto dan gambar berwarna), dan desain buku ajar dinilai ahli bidang studi/isi pembelajaran, ahli media pembelajaran, ahli desain buku ajar, dan mahasiswa memenuhi kriteria valid, praktis, dan efektif untuk digunakan sebagai sumber pembelajaran utama mata kuliah pengembangan media video pada mahasiswa Program Studi Teknologi Pendidikan FIP Universitas Negeri Makassar. Namun demikian, komentar ahli bidang studi/isi pembel-ajaran, adalah sebagai berikut: terdapat beberapa kata yang salah ketik, misalnya pada halaman 4 tertulis pengajaran seharusnya pembelajaran, halaman 6 tertulis guru, dosen seharusnya guru/ dosen, halaman 6 tertulis berulang-ulang seharusnya berulang kali, halaman 7 tertulis mendatangkan seharusnya menghadirkan, halaman 7 tertulis kabur seharusnya buram, halaman 9 tertulis ceoat seharusnya cepat, halaman 9 tertulis pada seharusnya dapat, halaman 10 tertulis dibawa seharusnya disaksikan, halaman 12 tertulis Betamax seharusnya Betacam, halaman 13 tertulis handcam seharusnya handycam, halaman 15 tertulis lensa seharusnya layar, halaman 15 tertulis listrik dari adaptor seharusnya listrik dan adaptor, halaman 15 tertulis tempat memasang tali handy kamera lensa seharusnya tempat memasang tali handycam, halaman 16 tertulis TILF seharausnya TILT, halaman 17 tertulis ekstrem seharusnya extreme, halaman 17 tertulis sangat seharusnya tampak. Komentar/saran ahli bidang studi/isi pembelajaran adalah sebaiknya jenis tripod diberi penjelasan tentang nama dan kegunaannya (Prof. Dr. Abd. Aziz Ahmad, M.Pd., 2018). Kata yang salah ketik/tulis dan komen-tar/saran ahli bidang studi/isi pembelajaran sudah diperbaiki/direvisi.

Penilaian ahli media pembelajaran, bahwa penyajian media grafis berupa foto dan gambar berwarna dalam buku ajar pengembangan media video sudah sesuai/ valid dengan maksud dan fungsinya untuk memperjelas isi pembelajaran dalam rangka pencapaian tujuan pembelajaran. Komentar/saran ahli media pembelajaran bahwa media yang disajikan sebagai mediator pencapaian tujuan pembelajaran sudah bisa diujicobakan (Dr. Pattaupi, M.Si., 2018). Dengan demikian peng-gunaan foto dan gambar berwarna sebagai media pelengkap/penjelas isi pembelajaran (teks) sudah sesuai atau valid. Desain buku ajar pengembangan media video dinilai oleh ahli desain buku ajar sudah valid dengan fungsinya sebagai buku ajar untuk mencapai tujuan pembelajaran. Komentar/ saran ahli desain buku ajar adalah tayangan gambar pada epitome perlu lebih faktual sesuai sasaran (Dr. Abd. Haling, M.Pd., 2018). Komponen-komponen buku ajar pengem-bangan media video sudah sesuai dengan letak dan fungsinya atau dengan kata lain sudah valid. 


\section{KESIMPULAN}

1. Produk buku ajar pengembangan media video pembelajaran yang dikembangkan memenuhi kriteria valid.

2. Produk buku ajar pengembangan media video pembelajaran yang dikembangkan memenuhi kriteria praktis.

3. Produk buku ajar pengembangan media video pembelajaran yang dikembangkan memenuhi kriteria efektif.

\section{DAFTAR PUSTAKA}

AECT. (1977). Definisi Teknologi Pendidikan (Satuan Tugas Definisi Terminologi AECT (Terjemahan). Jakarta: Penerbit CV. Rajawali.

Arsyad, A. (2014). Media Pembelajaran. Jakarta: PT. RajaGrafindo Persada

Degeng, I.N.S. (2013). Ilmu Pembelajaran: Klasifikasi Variabel untuk Pengem-bangan Teori dan Penelitian. Bandung: Aras Media.

Kurniawan, A. D. dan Nurlela, L. (2013). Pengembangan Buku Siswa Untuk Meningkatkan Proses dan Hasil Belajar Kompetensi Dasar Cornflake Cookies pada Siswa Tunagrahita SMA-LB Negeri Gedang Sidoarjo (e-journal boga Vol 2 No 1 Tahun 2013)

Riduwan, M. (2012). Dasar-Dasar Statistika. Bandung: Alfabeta

Sadiman, dkk. (2011). Media Pendidikan: Pengertian, Pengembangan, dan Pemafaatannya. Jakarta: PT. Raja Grafindo Persada

Sa'idah, Nusrotus. (2016). Pengembangan Buku Ajar Statistik Sebagai Penun-jang Perkuliahan (Jurnal Refleksi Edukatika Vol. 6. No. 2 Juni 2016)

Sanjaya, W. (2012). Perencanaan dan Desain Sistem Pembelajaran. Jakarta: Kencana Prenada Media Group.

Seels, B. \& Richey, C. (1994). Teknologi Pembelajaran: Definisi dan Kawasan-nya. Terjemahan Yusufhadi Miarso dkk. Jakarta: Unit Percetakan Universitas Negeri Jakarta.

Smaldino, S. L., Lowther, D. L., \& Russel J. D. (2008). Instructional Technology and Media for Learning $9^{\text {th }}$ Edition. New Jersey. Pearson Education, Inc.

Sugiyono. (2008). Metode Penelitian Pendidikan: Pendekatan Kuantita-tif, Kualitatif, dan R\&D. Bandung: Alfabeta.

Thiagarajan, Sivasailan, dkk. (1974). Instructional Development for Trining Teacher of Exceptional Children: A Source Book. Washington D.C.: National Center for Improvement of Educational System. (Online), (http://www.eric. ed.gov) diakses 22 Februari 2017.

Undang-Undang RI No. 12 Tahun 2012 Tentang Pendidikan Tinggi. (Online), (http://www.portal. Mah-kamahkonstitusi.go.id) diakses 22 Februari 2017. 